\title{
ESO-based iPI Common Rail Pressure Control of High Pressure Common Rail Injection System
}

\author{
Haoping WANG, Yang TIAN*, Dong ZHENG, \\ Nanjing University of Science \& Technology (NJUST), School of Automation, \\ Sino-French International Joint Laboratory of Automatic Control and Signal Processing (LaFCAS), \\ Nanjing 210094, China. \\ hp.wang@njus; tianyang@njust.edu.cn (*corresponding author)
}

\begin{abstract}
This paper presents an ESO-based iPI control for common rail pressure. First, a detailed mathematical model of High Pressure Common Rail Injection System (HPCRIS) is built. The mathematical model is validated by the software Matlab and commercial software AMESim. For the considered HPCRIS, an effective model free controller which is called Extended State Observer - based intelligent Proportional Integral (ESO-based iPI) controller is designed. And this proposed ESO-iPI controller is composed mainly of the referred ESO observer, and the iPI controller. Finally, to demonstrate the performances and effectiveness of the proposed controller, the proposed controller is implemented and compared with a conventional PID controller and Active Disturbance Rejection Control (ADRC), and their corresponding simulations are carried out.
\end{abstract}

Keywords: High pressure common rail injection system, common-rail pressure, ESO, iPI controller, ADRC, AMESim.

\section{Introduction}

In recent years, serious air pollutions have affected people's daily life. According to the survey of the environment protection department in 2015 , one of the main emission resources of $\mathrm{NO}_{\mathrm{x}}$ and $\mathrm{C}$ is from the transportation section, in which the emissions of diesel engine occupy the most important part. Thus improvement of the emission performance of diesel engine becomes a rigorous and important task. High Pressure Common Rail Injection System (HPCRIS) is a key technology to reduce the emission of diesel engine. Its function determines not only the injection-fuel pressure, but also the emission measurement of fuel-injection. High and steady common-rail pressure is important to diesel engine.

To study the control of common-rail pressure, a model that can describe the dynamics of the common-rail pressure is required firstly. Many researchers have built different common-rail pressure models, like an empirical common-rail pressure model in [1], a hybrid common-rail injection system model in [2], and a controloriented model in [12] which is adopted by most researchers.

In [13], Lino et al based on the referred controloriented model proposed a sliding mode rail pressure controller, while many other researchers based on classical PID controller, propose derived PID controllers for common rail pressure control, such like RBF neural network adaptive PID control in [10], feed forward fuzzy PID control in [6], and genetic algorithm nonlinear PID control in [20], etc.

For the pressure wave in the common rail caused by the discontinuous inlet fuel flow and the discontinuous outlet fuel flow, some different control methods have been applied to the rail pressure control, such as the QFT (quantitative feedback theory) method is introduced to regulate and control rail pressure [3], and a coordinated control strategy for the rail pressure using a metering unit and a pressure control valve in proposed in [9].

More recently, to improve the control performance of the considered common rail system, particularly with the consideration of the uncertainties, and external disturbance such as measurement noise, etc in system dynamics, a novel disturbance estimation and rejection control is designed for rail pressure control in [16]. From the above overview of the rail pressure control, the requirements for the rail pressure controller are: simple parameters tuning, good rejection to external disturbances, and easy adaptation to variable working conditions.

Thus in this paper, an Extended State Observer - based intelligent Proportional Integral (ESObased iPI) controller is designed for common rail pressure of HPCRIS. This proposed ESObased iPI control is based on new results from intelligent PID Control which employs an ultralocal model and algebraic based derivatives 
estimation of systems output signals [4-5]. While for the referred algebraic based derivatives estimation, it needs complex calculation steps and easily perturbed by external measurement noises. To improve the entire method performance, an extended state observer (ESO) which are derived from $[8,14]$ is proposed via the knowledge of the control and output signals [6].

The following paper is organized as follows: a detailed nonlinear model of HPCRIS is proposed in section 2, which is followed in section 3, the referred mathematical model of HPCRIS is validated both by MATLAB/Simulink and AMESim software. Then in Section 4, for the considered HPCRIS, a new ESO-based iPI controller is designed. Moreover to validate the proposed entire control, its corresponding simulation results which are implemented in both Matlab/Simulink and AEMSim environment, and compared with classic PID controller and ADRC are illustrated in section 5. Finally, some conclusions and future work comments are summarized in section 6

\section{Modeling of High Pressure Common Rail Injection System}

In this section, the working principle of the HPCRIS is firstly described, then based on the principles of the continuity equation, momentum equation and Newton's motion law, the dynamic model of HPCRIS which contains three sub-models of high pressure pump subsystem, common rail subsystem, and injector subsystem is established in detail.

\subsection{Description and modeling of HPCRIS}

The major function of HPCRIS is to deliver high pressure fuel based on the working condition of engine. Its corresponding architecture is shown in Figure 1. The main elements of the system are the high pressure pump, the common rail, the injectors and the electronic control unit (ECU). The tank supplies the low pressure to the high pressure pump in which raises to the desired pressure. The high pressure pump sends high pressure fuel to the common rail, the common rail distributes the fuel to each injector and the injectors inject high pressure fuel to the cylinder.

The ECU which is the core center of HPCRIS determines the pressure of fuel based on the

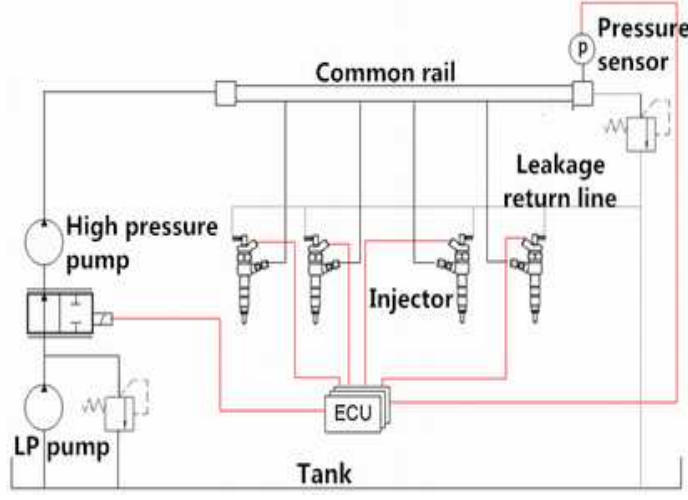

Figure 1. High pressure common rail injection system (HPCRIS)

work condition of the engine by according to the acquisition of various vehicle sensor signals. The HPCRIS has a complex injection process, there are many factors affect the performance of fuel injection, such as fuel leakage between various components, the elastic deformation of high pressure fuel pipe, fuel compressibility under high temperature and high pressure, and flow rate loss when the fuel flows through variable cross-section etc.

Common rail pipe stores the high pressure fuel supplied from high pressure pump also provides the high pressure fuel to the injectors. Thus, in the process of modelling mainly considers three parts: high pressure pump, common rail pipe and injectors. Symbols and their descriptions are listed in Table 1.

In the model, the bulk modulus of elasticity $E$ which expresses the compressibility of the fuel:

$$
E=-\frac{d P}{d V / V}=\frac{d P}{d \rho / \rho}
$$

where the increase of $d P$ causes the volume decrease of a unit volume of liquid $-d V$, and $d V / V$ is dimensionless.

From (1), the time derivative of the fuel pressure can be obtained [15]:

$\frac{d P}{d t}=-\frac{E}{V} \cdot \frac{d V}{d t}$

where $V$ is the instantaneous volume of the chamber, $d V / d t$ expresses the volume changes caused by mechanical parts piston, the intake and the outtake flows. Considering the factors affect the volume change of the fuel, (2) can be rewritten as:

$$
\frac{d P}{d t}=-\frac{E}{V} \cdot\left(\frac{d V_{0}}{d t}-Q_{\text {in }}+Q_{\text {out }}\right)
$$


Table 1. Nomenclatures

\begin{tabular}{|l|c|}
\hline \multicolumn{1}{|c|}{ Description } & Symbol \\
\hline Bulk modulus of elasticity & $E$ \\
inlet fuel flow of high pressure pump & $Q_{p}$ \\
leakage fuel flow of high pressure pump & $Q_{p l}$ \\
fuel pressure of high pressure pump & $P_{p}$ \\
volume of high pressure pump & $V_{p}$ \\
volume of common rail pipe & $V_{c r}$ \\
high pressure pump cross-sectional area of outlet port & $S_{p c r}$ \\
common rail fuel pressure & $P_{c r}$ \\
camshaft rotational speed & $\omega_{r p m}$ \\
camshaft angle & $\theta$ \\
injection pressure & $P_{i n j k}$ \\
cross-sectional area of the $k$-th injector & $S_{c r i k}$ \\
volume of the $k$-th injector & $V_{i n j k}$ \\
injection fuel flow from the k-th injector to cylinder & $Q_{c y l k}$ \\
cylinder pressure & $P_{c y l k}$ \\
the orifice area of the injector nozzle & $S_{i n j k}$ \\
\hline
\end{tabular}

which represents the basic pressure dynamics equation in each control volume, and $Q_{i n}$ denotes the intake flow and $Q_{\text {out }}$ depicts outtake flow, and $d V_{0} / d t$ represents the volume change rate caused by the mechanical piston, which will be specified for the high pressure pump, the common rail pipe and the injector, respectively. In exception of the high pressure pump, all the elements in HPCRIS have a constant volume.

Based on the energy conservation law, the intake and outtake flows $Q_{i n}$ and $Q_{\text {out }}$ can be expressed as follow

$Q=\operatorname{sign}(\Delta P) \cdot \mu \cdot S_{0} \cdot \sqrt{\frac{2|\Delta P|}{\rho}}$ where $\operatorname{sign}(\Delta P)$ represents the sign function affecting the flow direction, $\mu$ is the discharge coefficient, $S_{0}$ is the corresponding orifice section, $\rho$ is the duel density and $\Delta P$ is the fuel pressure difference across the referred orifice.

\subsection{High pressure pump subsystem}

The high pressure pump subsystem consists of three identical hydraulic rams mounted on the same shaft with a relative phase of $120^{\circ}$. Since the pump is powered by the camshaft, its evolution depends on the engine speed. It is connected by a small orifice to the low pressure circuit and by a delivery valve with a conical seat to the high pressure circuit.

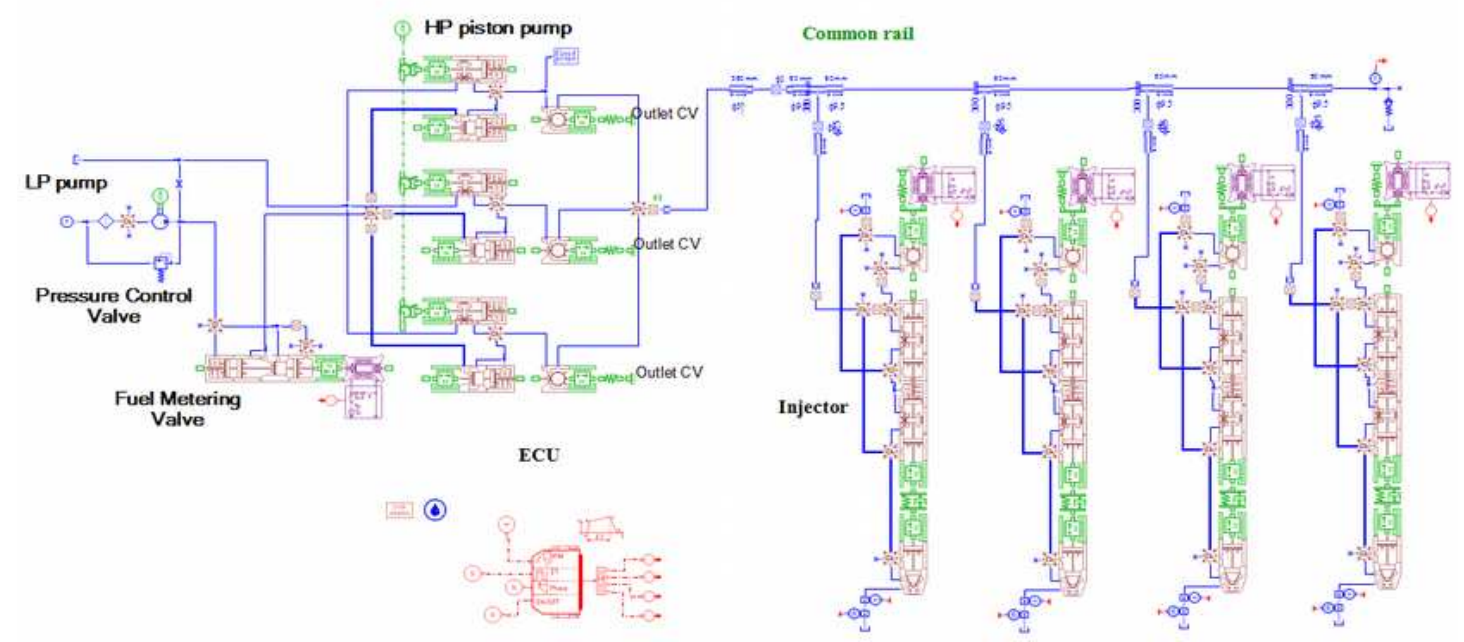

Figure 2. High pressure common rail injection system built in AMESim 
According to (3), the pressure dynamic equation for the high pressure pump subsystem can be modelized as follow:

$$
\begin{aligned}
& \frac{d P_{p}}{d t}=\frac{E}{V} \cdot\left(S_{p} \omega_{r p m} \frac{d h_{p}}{d \theta}+Q_{p}-\right. \\
& \left.-\operatorname{sign}\left(P_{p}-P_{c r}\right) \mu_{P} S_{p c r} \sqrt{\frac{2}{\rho}\left|P_{p}-P_{c r}\right|-Q_{p l}}\right)
\end{aligned}
$$

\subsection{Common rail subsystem}

The dynamic of the rail pressure is obtained by considering the balance between the high pressure pump inlet flow and injectors' outlet flows.

The common rail pipe distributes the high pressure fuel supplied by the high pressure pump subsystem to all the injectors and stores up the pressure. As the flow sustained by the high pressure pump is discontinuous, a pressure drop in the rail due to injections when no intake flow is sustained, while the pressure rises when the delivery valve opens and injectors close. Thus, to reduce the rail pressure oscillations, the regulator acts only during a specific camshaft angular interval, and its action synchronized with the pump motion.

Based on (3), the common-rail fuel pressure dynamics of common rail subsystem can be modeled as follow

$$
\begin{aligned}
\frac{d P_{c r}}{d t} & =\frac{E}{V}\left(\operatorname{sign}\left(P_{p}-P_{c r}\right) \mu_{p} S_{p c r} \sqrt{\frac{2}{\rho}\left|P_{p}-P_{c r}\right|}-\right. \\
& \left.-\sum_{k=1}^{4} \operatorname{sign}\left(P_{c r}-P_{i k}\right) \mu_{i k} S_{c r i k} \sqrt{\frac{2}{\rho}\left|P_{c r}-P_{i k}\right|}\right)
\end{aligned}
$$

\subsection{Injector subsystem}

The common rail subsystem supplies four injectors for four cylinders of the engine. The referred injector consists of the solenoid valve, gag bit, ball valve, control piston and needle.

Derived from (3), the fuel pressure dynamics of injector can be obtained as follow

$$
\begin{array}{r}
\frac{d P_{i n j k}}{d t}=\frac{E}{V_{i n j k}}\left(\operatorname{sign}\left(P_{c r}-P_{i n j k}\right)\right. \\
\mu_{i n j k} S_{c r i k} \sqrt{\frac{2}{\rho}\left|P_{c r}-P_{i n j k}\right|}- \\
-\operatorname{sign}\left(P_{i n j k}-P_{c y j k}\right) E_{T k} \\
\mu_{i k} S_{i n j k} \sqrt{\left.\frac{2\left(P_{i n j k}-P_{c y l k}\right)}{\rho}\right)}
\end{array}
$$

\section{Model Validations by Matlab/Simulink and AMESim}

In this section, to demonstrate the validity of the proposed mathematical model, the proposed HPCRIS is implemented firstly on the Matlab/Simulink, then the obtained simulation results are further compared with the simulation results obtained from real-time physical system based software - AMESim (Advanced Modeling Environment for performing Simulation of engineering systems). The AMESim was created by French Imagine Company and bought by LMS company in Belgium is a multi-domain complex system modeling and simulation platform. The user could establish their system model and obtain system transient and steady state performances by system analyzing, calculation and simulation, and enables the users to focus on the physical design instead of emphasizing on complicated mathematical modeling. What is more noticeable is that the AMESim supplies the IFP engine library targets on the engines, provides about 4500 multi-flied models, including the professional HPCRIS system model, experimented and validated against real-time systems.

The performance of the referred HPCRIS whose mathematical model is presented in section II is illustrated in Figure 3-10. The simulation setup consists of a reciprocating pump, a common rail and four electro-injectors. The camshaft speed is $2000 \mathrm{rpm}$. The parameters of the model are given in Table 2.

Table 2. Common rail system model parameters

\begin{tabular}{|l|l|r|}
\hline \multicolumn{1}{|c|}{ Sub-system } & \multicolumn{1}{|c|}{ Quanlity } \\
\hline \multirow{4}{*}{ High pressure pump } & fuel pressure in tank & Value \\
& pump volume & $125.48 \mathrm{~mm}^{3}$ \\
& plunger diameter & $7.6 \mathrm{~mm}$ \\
& fuel leakage gap & $0.0025 \mathrm{~mm}$ \\
\hline \multirow{2}{*}{ Common rail pipe } & main body volume & $28.4 \mathrm{~mm}^{3}$ \\
& diameter of inlet orifice & $3 \mathrm{~mm}$ \\
\hline \multirow{2}{*}{ Injector } & injector internal diameter & $4.5 \mathrm{~mm}$ \\
& nozzle diameter & $0.12 \mathrm{~mm}$ \\
& nozzle number & 4 \\
\hline
\end{tabular}


Figure 3 shows the movement of the pistons in the high pressure pump plunger. The alternative motion and pressure of each piston with the phase shaft of 120 degree between each of them. Figure 4 illustrates the outtake flow rate of the high pressure pump, the curve of the flow rate changes with the motion of the pistons. The common rail pressure curve is presented in Figure 5, the change of the common rail pressure is similar to the outtake flow rate of high pressure pump. In these figures, the dynamic of the high pressure pump which can be well simulated and validated both on MATLAB/Simulink and AMESim are basically identical.

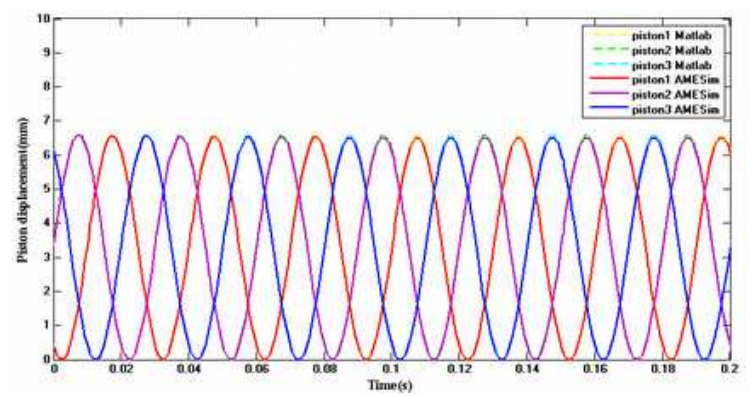

Figure 3. Displacement of high pressure pump piston $(\mathrm{mm})$

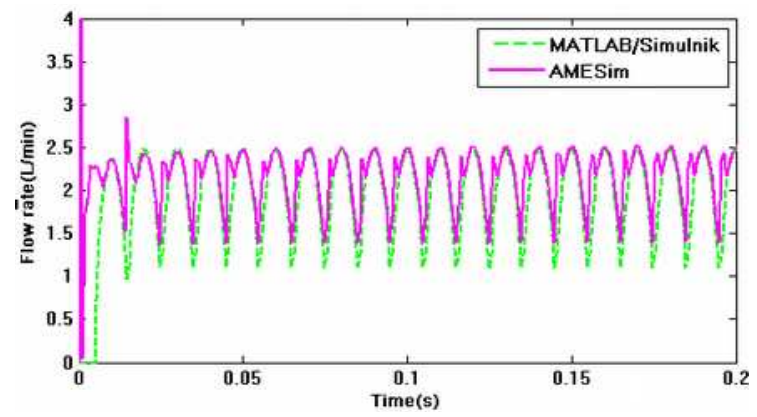

Figure 4. Flow rate of high pressure pump (L/min)

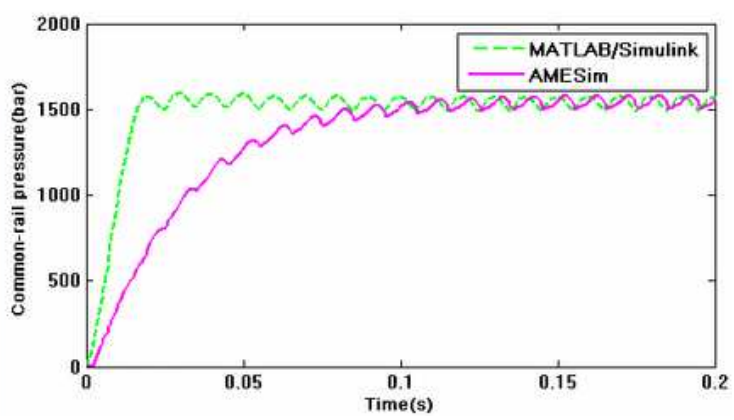

Figure 5. Common rail pressure (bar)

Figure 6 is the current signal that driving the solenoid valve, Figure 7 shows the displacement of the solenoid valve. As we can see in these figures, when the current increases to the higher value, it ensures the opening of the solenoid valve. Then the current reduce to

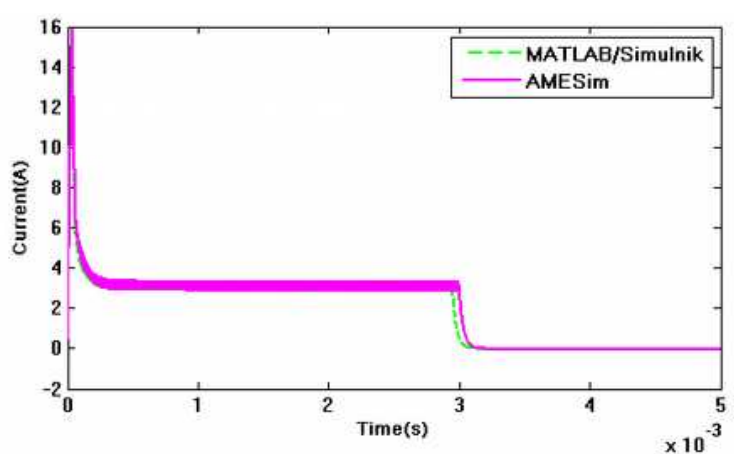

Figure 6. Current signal of solenoid valve

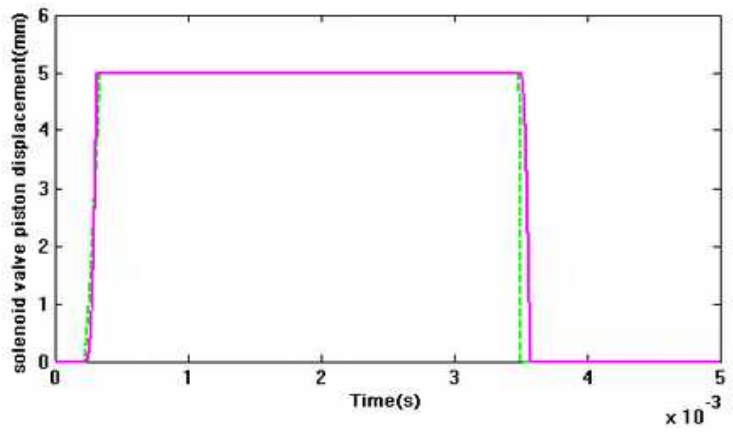

Figure 7. Displacement of solenoid valve

the holding current, the time during which the holding current acting defines the time that how long the valve opens and determine how much the fuel injected. After the current reduces to zero, the valve closes.

Figure 8 and Figure 9 illustrate respectively the pressure dynamics in control and accumulator

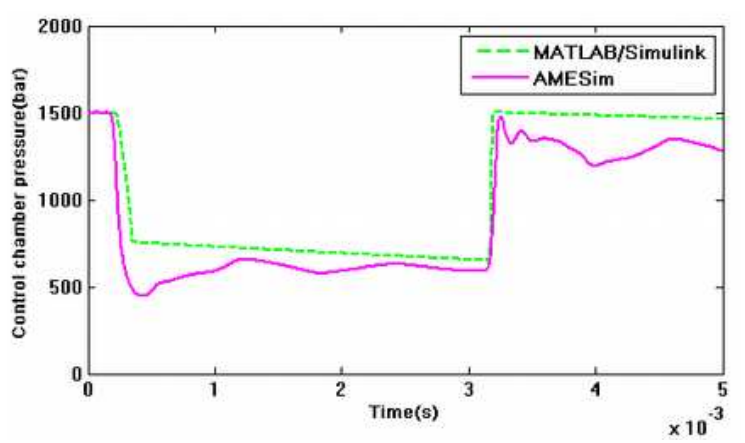

Figure 8. Pressure in control chamber

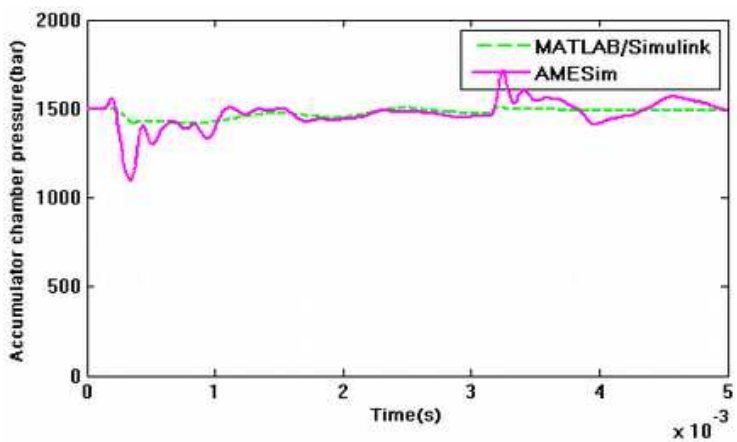

Figure 9. Pressure in accumulator chamber 
chambers. When the solenoid valve opens, the fuel pressure in the control chamber drops sharply, and the pressure in the accumulator chamber drops equally. When the valve is closed, the pressure increases rapidly to common rail pressure. Figure 10 presents the injection flow rate, the two curves change similarly to each other.

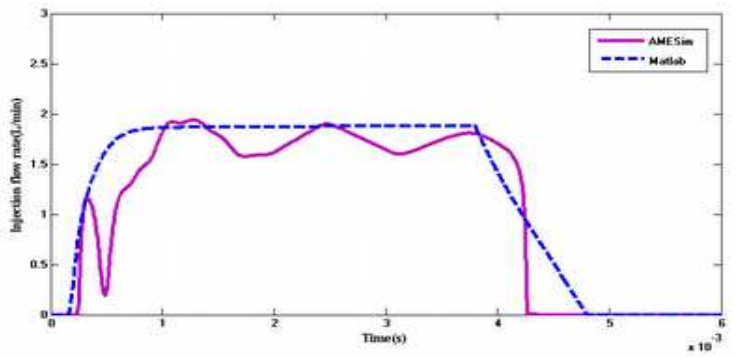

Figure 10. Injection flow rate (L/min)

As the simulation results shows, the proposed mathematical model can describe the dynamic of HPCRIS correctly. Thus, this proposed HPCRIS model can be used to design the common rail pressure controller.

\section{ESO-based iPI Common Rail Pressure Control}

For the considered nonlinear HPCRIS, an ESObased iPI common rail pressure control is designed in this subsection.

\subsection{Model-free controller design}

For designing the proposed controller, the referred $\mathrm{Qp}$ is selected as the control input, according to [17], the following ultra-local model can be used to designate the referred "complex" mathematical model as follow

$y^{(v)}=F+\alpha u$

where $y^{(v)}$ is the derivative of order $v$ of output $y$, and generally in practice, $v=1$ or 2 ; $\alpha$ is a non-physical constant parameter and chosen such that $\alpha u$ and $y^{(v)}$ are of the same magnitude. The values of $v$ and $\alpha$ are selected and imposed by practitioners. And $F$ which represents the unknown term and can be estimated via the signals of control input $u$ and output $y$, includes not only the unknown structure of the system but also external disturbances.

\subsection{Intelligent PI (iPI) Control}

Then with $v=1$ in (8), and the considered HPCRIS can be denoted as follow
$\dot{y}=F+\alpha u$

Close the loop via the intelligent proportionalintegral controller, or iPI [18], one obtains

$u=-\frac{F_{e s t}-\dot{y}_{d}-\left(K_{P} e+K_{I} \int e\right)}{\alpha}$

where $y_{d}$ is the desired output reference trajectory, $F_{\text {est }}$ is the estimation of $F, e=y_{d^{-}} y$ is the output trajectory tracking error, and $K_{p}$ and $K_{i}$ are the usual tuning gains of PI.

Replacing (10) to (9), one yields

$$
\dot{y}=F+\alpha\left(-\frac{F_{e s t}-y_{d}^{(v)}-\left(K_{P} e+K_{I} \int e\right)}{\alpha}\right)
$$

which leads to

$$
\dot{e}+K_{P} e+K_{I} \int e=F_{e s t}-F
$$

If $F_{e s t}$ can be approximately equal to $F$, and take the derivative of (11b) leads to

$$
\ddot{e}+K_{P} \dot{e}+K_{I} e \approx 0
$$

Then the parameters of $K_{P}$ and $K_{I}$ in iPI controller can be calculated by the pole placement technique. This is a major benefit when compared with the tuning of "classical" PIDs.

\subsection{Estimation of $F$}

The value of $F$ in (9) is updated at each sampling time from the current measurement of the output and the knowledge of input with an infinitesimal value delay, the estimation of $F$ can be estimated by time delay technique as follow:

$$
F_{\text {est }}(t)=\dot{y}(t)-\alpha u(t-\tau)
$$

where $\tau$ is a small time interval. The smaller the delayed time $\tau$ is, the better the estimation performance is. Although the time delay estimation technique is simple, its performance is greatly affected by measurement noise.

Thus in this paper, $F_{\text {est }}$ is proposed to be obtained by application of Extended State Observer (ESO) which is a new state observer that firstly proposed in [11], and it's a special state observer that designed for nonlinear uncertain systems. The ESO which expanses the state variable of system enable to track the state variables of controlled system and estimate the referred un-modeled dynamics of controlled system and external disturbance. A 
second order ESO can be designed as follows by according to [19][20]:

$$
\begin{aligned}
& e_{1}(t)=\hat{y}(t)-y(t) \\
& \dot{\hat{y}}(t) z_{1}(t)-\beta_{1} e_{1}(t)+\alpha u(t-\tau) \\
& \dot{z}_{1}(t)=-\beta_{2} e_{1}(t)
\end{aligned}
$$

where $y$ is output $P_{c r}$, measured and to be controlled, $u$ is the control input of the fuel flows of the high pressure pump inlet port $Q_{p}$, $z_{1}$ is the estimation of $F$, and $\beta_{1}$ and $\beta_{2}$ are the extended observer gain. The larger of $\beta_{i}$ $(i=1,2)$, the smaller of the error. And to make the steady observer error acceptable, the selected values of $\beta_{2}>\beta_{1}>0$ should be satisfied. Then the entire proposed ESO-based iPI controller can be summarized as follows

$$
u=-\frac{F_{e s t}-\dot{y}_{d}+K_{P} e+K_{I} \int e}{\alpha}
$$

with

$$
\begin{aligned}
& F_{\text {est }}=z_{1}, \\
& e_{1}(t)=\hat{y}(t)-y(t), \\
& \dot{\hat{y}}(t)=z_{1}(t)-\beta_{1} e_{1}(t)+\alpha u(t-\tau), \text { and } \\
& \dot{z}(t)=-\beta_{2} e_{1}(t) .
\end{aligned}
$$

Its corresponding realization architecture can be illustrated in Figure 11.

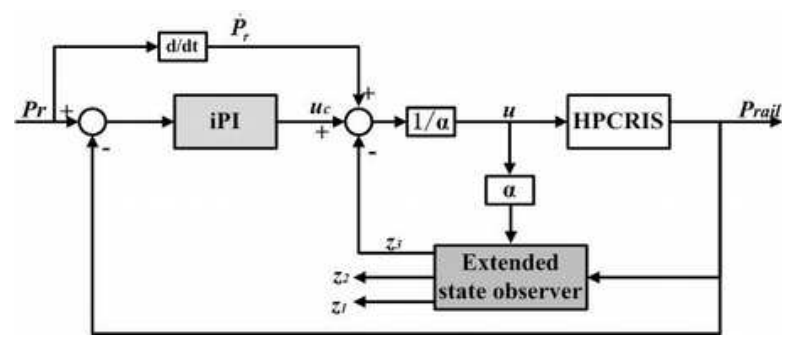

Figure 11. ESO-based iPI controller

\section{Control Application Results of ESO-based iPI Controller}

In this subsection, to validate the proposed ESO-based iPI controller tracking and disturbances rejection performance, it's applied to control the common rail pressure of the HPCRIS which are simulated and validated in both Matlab / Simulink and AMESim environment. Moreover, the proposed method is compared with PID and ADRC controllers.

\subsection{Simulation results compared with classical PID controller and ADRC}

The ESO-based iPI controller parameters can be selected as $K_{p}=45, K_{I}=200$; The ESO gains: $\beta_{I}=2000, \quad \beta_{2}=2000 . \quad$ To demonstrate the performance of the ESO-based iPI controller, a compared classical PID controller whose parameters are tuned according to paper [21] is designed.

The control law of ADRC based rail pressure control whose structure is illustrated in Figure 12 is defined as follows

$$
\mid \begin{aligned}
& v_{1}=v_{1}+h v_{2} \\
& v_{2}=v_{2}+h f v \\
& e=z_{1}-y \\
& f e=f a l(e, 0.5, h), \quad f e_{1}=f a l(e, 0.25, h) \\
& f a l(e, \alpha, \delta)= \begin{cases}\frac{e}{\delta^{1-\alpha}} & |x| \leq \delta \\
|e|^{\alpha} \operatorname{sign}(e) & |x| \geq \delta\end{cases} \\
& z_{1}=z_{1}+h z_{2}-\beta_{01} e \\
& z_{2}=z_{2} h\left(z_{3}+b_{0} u\right)-\beta_{02} f e \\
& z_{3}=z_{3}-\beta_{03} f e_{1} \\
& e_{1}=v_{1}-z_{1}, \quad e_{2}=v_{2}-z_{2} \\
& u=\frac{k f a l_{2}(e, \alpha, \delta)-z_{3}}{b_{0}}
\end{aligned}
$$

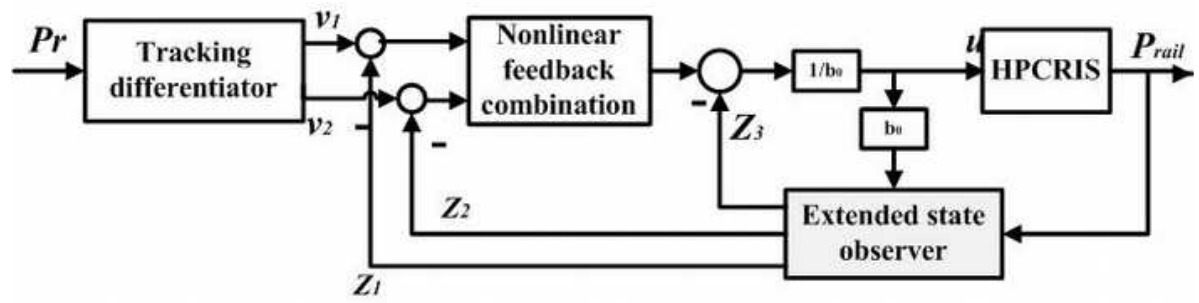

Figure 12. ADRC controller structure 
According to above equation (16), the parameters of ADRC are selected as follows: $k=5, \alpha=0.1, \delta=0.5$ The ESO gains: $\beta_{I}=1000$, $\beta_{2}=2000$. With the developed ESO-based iPI controller and the compared conventional PID controller and ADRC, we implemented them to control the referred nonlinear HPCRIS whose detail mathematical model is presented and validated respectively in section 2 and 3 . Their corresponding MATLAB / Simulink based numerical results are illustrated in Figure 13, Figure 14, while the AMESim based simulation results are shown in Figure 15 and Figure 16.

From the simulation results showed in Figure $13-14$, it can be seen easily from these figures that under the same simulation condition, the overshoot of the proposed ESO-based iPI controller is significantly smaller than the classical PID and ADRC controller.

Then concerning the AMSim results, from Figure 15 , one notices that due to the injector's injection flow, the high pressure oscillations exist. The PID controller overshoots about 200 bar and the steady-state error is about \pm 100 bar. The overshoot of ADRC is about 10 bar higher than the proposed controller, and its oscillation is equally bigger than the proposed controller. And from Figure 16, one discovers that the steady error of PID and ADRC controllers are bigger than the proposed ESO-based iPI controller. Moreover the proposed controller ensures relatively fast tracking performances with reduced fluctuation of common rail pressure compared to PID and ADRC controllers.

\section{Disturbance rejection validations}

In real HPCRIS, the control signal will be affected by external white measurement noise. To validate the disturbance rejection performance of the proposed ESO-based iPI controller, the white noise with the $10 \%$ of its output amplitude is added to the closed control loop system, and its corresponding results in MATLAB/Simulink and AMSim are illustrated respectively in Figure 17 and Figure 18.

From these two figures, one can notice that the proposed ESO-based iPI controller ensures the good rejection performances to external white noises. Their obtained corresponding tracking common rail pressures in each simulation platform of MATLAB/Simulink and AMSim almost coincide being identical under the condition of with or without white measurement

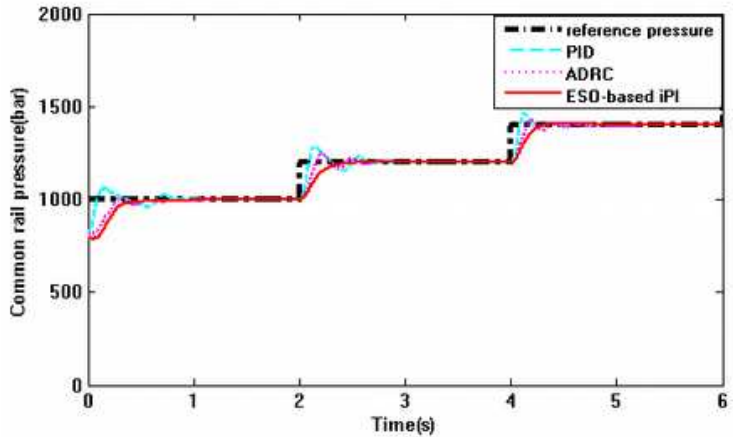

Figure 13. Simulation results of rising step rail pressure ref. in MATLAB/Simulink

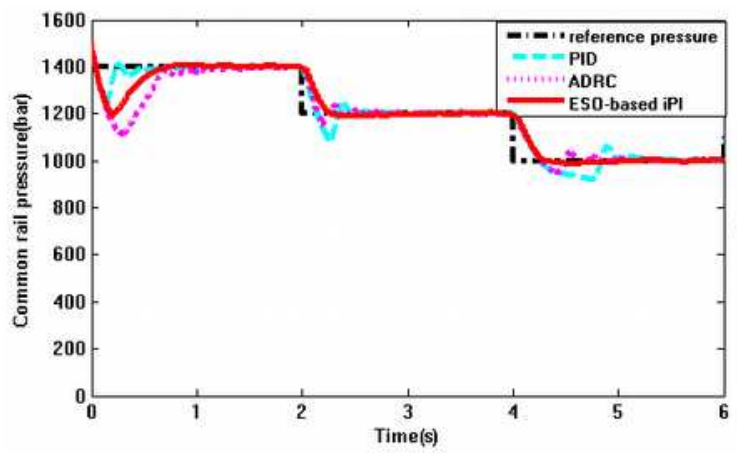

Figure 14. Simulation results of descent step rail pressure ref. in MATLAB/Simulink

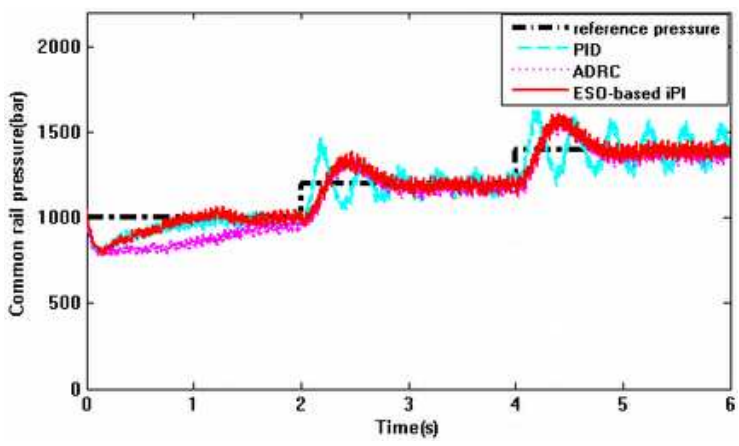

Figure 15. Simulation results of rising step rail reference in AMESim

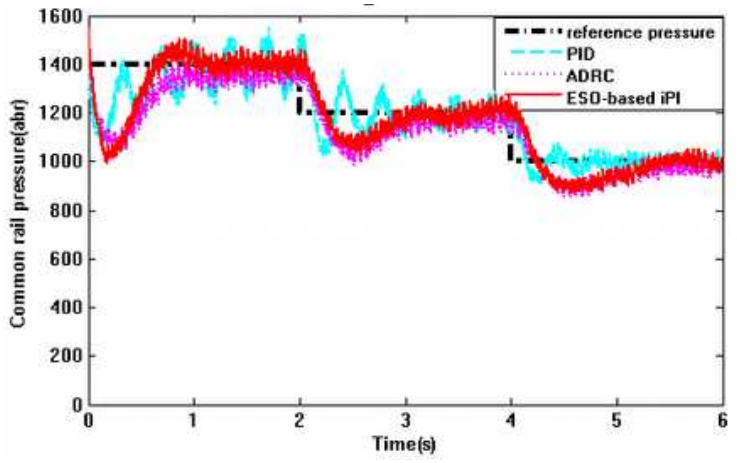

Figure 16. Simulation results of descent step rail pressure reference in AMESim

noise. In addition to these simulation results, it may be easily noted that the proposed controller is also capable of rapid tracking of the desired common rail pressure references. 


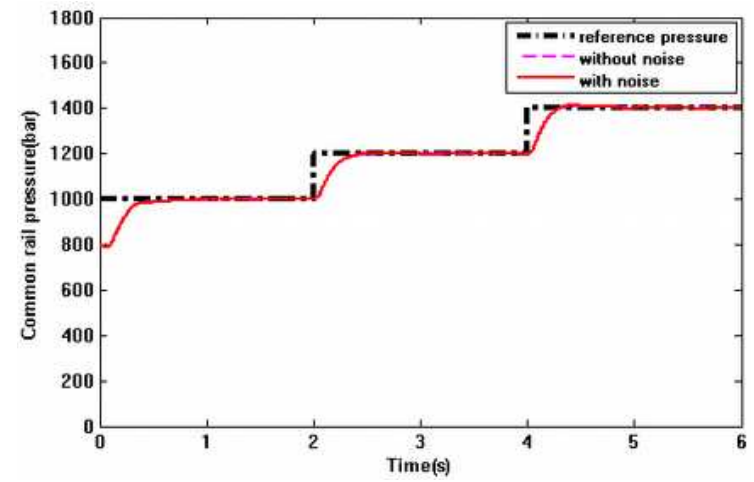

Figure 17. Disturbance rejection validation in MATLAB/Simulink

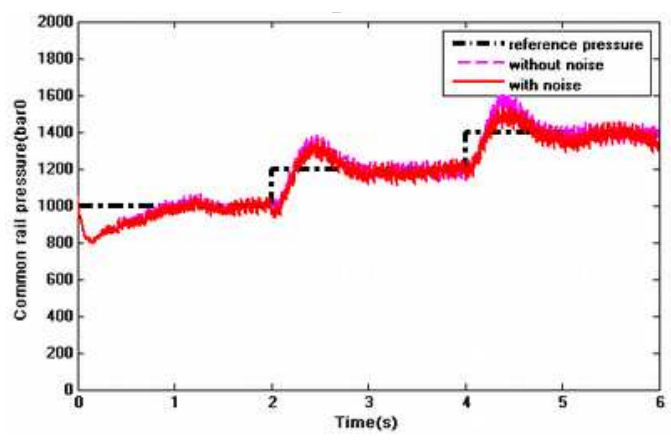

Figure 18. Disturbance rejection validation in AMESim

\section{Conclusion}

In this paper, an ESO-based iPI common rail pressure control of HPCRIS is presented. The proposed HPCRIS model is proposed and implemented firstly in Matlab/Simulink, and then validated on the commercial software AMESin. Based on the referred HPCRIS, the ESO-based iPI controller which contains an ultra-local model with extended state observer have been designed, and implemented and compared with PID and ADRC methods both on Matlab/Simulink and AMESim. From the simulation results obtained, one may conclude that the proposed ESO-based iPI controller demonstrates better performances in overshoot, tracking accuracy and rejection capabilities to external noise and unknown uncertainties of the controlled systems.

\section{Acknowledgements}

This work was partially supported by the National Natural Science Foundation of China (61304077), by International Science \& Technology Cooperation Program of China (2015DFA01710), by the Natural Science
Foundation of Jiangsu Province (BK20130765), by the Specialized Research Fund for the Doctoral Program of Higher Education of China (20123219120038), by the Chinese Ministry of Education Project of Humanities and Social Sciences (13YJCZH171), by the 11th Jiangsu Province Six talent peaks of high level talents (2014_ZBZZ_005).

\section{REFERENCES}

1. ARSIE, I., F. Di GENOVA, C. PIANESE, Development and Identification of Phenomenological Models for Combustion and Emissions of Commonrail Multi-jet Diesel Engines, SAE Tech Paper, 2004.

2. BALLUCHI,J A, A. BICCHI, E. MAZZI, Hybrid Modelling and Control of the Common Rail Injection System, Hybrid Systems: Computers and Control Springer Berl Heide, 2006, pp. 79-92.

3. CHATLATANAGULCHAI, W, T. AROONSRISOPON, K. WANNATONG, Robust Common-rail Pressure Control for a Diesel-Dual-Fuel Engine using QFT-based Controller, SAE Paper. 2009.

4. FLIESS, M., C. JOIN, Model-free Control and Intelligent PID Controllers: Towards a Possible Trivialization of Nonlinear Control, IFAC Proceedings., vol. 15, 2009, pp. 1531-50.

5. FLIESS, M., C. JOIN, Stability Margins and Model-free Control: A First Look, Proceedings of European Control Conference, (ECC), 2014, pp. 454-9.

6. FLIESS, M., H. SIRA-RAMÍREZ, An Algebraic Framework for Linear Identification, ESAIM Control Optim Calc Var, Vol. 9, 2003, pp. 151-68.

7. GÉdOUIN, P. A., E. DElaleAu, J. M. BOURGEOT, C. JOIN, S. A. CHIRANI, S. CALLOCH, Experimental Comparison of Classical PID and Model-free Control: Position Control of a Shape Memory Alloy Active Spring, Control Eng Pract., Vol. 19, 2011, pp. 433-41.

8. HAN J., From PID to Active Disturbance Rejection Control, IEEE Trans. Ind. Electron., vol. 56, 2009, pp. 900-6. 
9. HONG, S., H. SHIN, J. SOHN, I. PARK, M. SUNWOO, Coordinated Control Strategy for the Common-rail Pressure using a Metering Unit and $A$ Pressure Control Valve in Diesel Engines, Journal of Auto Engineering, 2014, pp. 1-13.

10. JI, Z., X. XIE, Z. SUN, P. CHEN, Rail Pressure Control of Common Rail Diesel Engine based on RBF Neural Network Adaptive PID Controller, Proc 2011 Int Conf Electron Mech Eng Inf Technol, 2011, pp. 1122-5.

11. KOUREMENOS, D. A., D. T. HOUNTALAS, A. D. KOUREMENOS, Development and Validation of a Detailed Fuel Injection System Simulation Model for Diesel Engines, SAE Technical Paper, 1999.

12. LINO, P., B. MAIONE, A. RIZZO, Nonlinear Modelling and Control of a Common Rail Injection System for Diesel Engines, Appl Math Model, vol. 31, 2007, pp. 1770-84.

13. LINO, P., B. MAIONE B, A. RIZZO, A Control-oriented Model of a Common Rail Injection System for Diesel Engines, 10th IEEE Conf, Emer Tech and Fact Auto, 2005, pp. 1-7.

14. LI. M., D. LI, J. WANG, C. ZHAO, Active Disturbance Rejection Control for Fractional-order System, ISA Trans vol. 52, 2013, pp.365-74.

15. LINO. P., B. MAIONE, A. RIZZO, A Control-oriented Model of a Common Rail Injection System for Diesel Engines,
2005 IEEE Conf Emerg Technol Fact Autom , 2005.

16. LIU, Q., X. GONG, Y. HU, H. CHEN, Active Disturbance Rejection Control of Common Rail Pressure for Gasoline Direct Injection Engine, Proc Ame Control Conf, 2013, pp. 2202-2207.

17. LI, M., D. LI, J. WANG, C. ZHAO, Active Disturbance Rejection Control for Fractional-order System, ISA Trans., Vol. 52, 2013, pp. 365-74.

18. MENHOUR, L., B. d'ANDREA-NOVEL, M. FLIESS, H. MOUNIER, Multivariable Decoupled Longitudinal and Lateral Vehicle Control: A Model-free Design, Proceedings of IEEE Conference on Decision Control, 2013, pp. 2834-9.

19. PAN, D., F. GAO, Y. MIAO, Cosimulation Research of a Novel Exoskeleton-human Robot System on Humanoid Gaits with Fuzzy-PID/PID Algorithms, Adva in Eng Soft, vol. 79, 2015, pp. 36-46.

20. REN, W., X. SHI, S. JIAO, C. ZHU, Q. ZHANG, Research on Rail Pressure Control of Diesel Engine based on Genetic Algorithm Nonlinear PID, 2011 IEEE Int Conf Comput Sci Autom Eng, 2011, pp. 67-71.

21. SU, H., G. HAO, P. LI, X. LUO, Feed Forward Fuzzy PID Controller for Common-Rail Pressure Control of Diesel Engine, Meas Technol Mechatronics Autom (ICMTMA), 2010. 